\title{
The Y-Shaped Designer-Connective Competences as Key to Collaboration across Disciplines
}

\author{
Jan Eckert ${ }^{1}$ \\ ${ }^{1}$ Department of Arts and Design, Lucerne University of Applied Science and Arts, Emmenbrücke, Switzerland \\ Correspondence: Jan Eckert, Department of Arts and Design, Lucerne University of Applied Science and Arts, \\ Nylsuisseplatz 1, 6020, Emmenbrücke, Switzerland. Tel: 41-41-248-6157. E-mail: jan.eckert@hslu.ch
}

Received: April 30, 2017

Accepted: June 16, 2017

Online Published: June 22, 2017

doi:10.5539/jel.v6n4p137

URL: http://doi.org/10.5539/jel.v6n4p137

\begin{abstract}
This paper reports on the re-development of our MA curriculum in design. Main objective of this development is a more practice- and project-based MA Curriculum that delivers connective competences for the collaboration across disciplines, rather than specializing in a specific design domain. For design education, we therefore propose a re-visited model of T-shaped skills by proposing the Y-shaped Designer, who acts in collaborations across disciplines thanks to a disciplinary root, a clearly perceived role and the ability to generate multimodal design outputs. The paper's discussion is based on a study of the current shift in the Swiss Creative Economy, an alumni survey, a literature review focusing undisciplinarity and a series of expert-workshops, that led to the identification of the required skills our graduates need to successfully connect with a globalizing creative economy. First results are a re-definition of the competences and learning goals targeted in the new curriculum, as well as a set of didactical approaches extending the curriculum to what is meant to become a real-world lab for MA students in design.
\end{abstract}

Keywords: connective competences, design education, multimodal literacy, situative learning goals, undisciplinarity, Y-shaped skills

\section{Introduction}

In the design community, the design generalist mostly is met with skepticism. Voices arise such as "When design can address everything, what is still left at the core of design?" (Ma, 2015, p. 1970). At the same time, a growing amount of "ill-defined" (Cross, 2006) and "wicked problems" (Rittel \& Webber, 1973; Buchanan, 1992) is extending into a globalized context addressed by design and Design Thinking. In doing so, the latter is increasingly gaining importance and as described by Lucy Kimbell is establishing in three different ways (Kimbell, 2011, p. 297) by proposing "a cognitive style aiming at solving problems" (Cross, 2006; Lawson, 2005), "a general theory" (Buchanan, 1992) or as "an organizational resource for businesses and organizations looking for innovation” (Brown, 2009; Dunne \& Martin, 2006). Eight years after its establishment, our MA curriculum in design is currently undergoing an important development in terms of its structure, main contents and goals. At the core of this process stands the question whether a master program in design should provide a curriculum that is focusing the specialization in a specific design discipline or whether it should facilitate interdisciplinary skills, which allow graduates to embed into different markets characterized by multidisciplinary and collaborative work environments. Whether this shift in our MA curriculum really leads to a better employability of our graduates, will be shown in a few years (as soon as first graduates will embed into the professional field). Consequently, this paper is not aiming to provide a complete conclusion on the questions approached but rather reports on those results which have been elaborated to have a basis for the implementation of our future MA curriculum. From a methodological point of view, these first insights are based upon an extended literature review focusing the undisciplinary, an alumni survey, the Swiss Creative Economy report (Weckerle et al., 2016), a poster discussion during the "REDO-Cumulus Conference 2017" in Kolding, Denmark, as well as a series of sounding-boards with representatives of Swiss associations in the creative domain (e.g., Swiss Design Association-SDA) and workshops with faculty from BA and MA programs in: Graphic Design, Illustration, Product Design, Textiles, Camera Arts, Design Management and Service Design. To give a more structured overview on the first insights, the paper focuses the following three aspects:

a) Which are the current shifts in the Swiss Creative Economy that drive the design discipline's evolution? 
b) Can this shift be met with an undisciplinary design approach, a term coined by Marshall and Bleecker (Marshall \& Bleecker, 2010) and subsequently picked up by design educators Craig Bremner and Paul Rodgers (Bremner \& Rodgers, 2013).

c) How might a MA curriculum support our student's future role in their occupation by proposing a Y-shaped skill model, which pinpoints connecting competences at the junction between the disciplinary root and the ability to collaborate across disciplines.

\section{An Economy-Driven Shift in Design Education?}

According to the last Swiss Creative Economy report (Weckerle et al., 2016, p. 65), two thirds of the creative jobs provided in the Swiss Creative Economy can be described as so called Embedded Creatives (Figure 1). Other than "Creative Specialists (...) employed in a creative industry in a creative occupation" (Weckerle et al., 2016, p. 83), the Embedded Creative works in a context that primarily is not aiming at creative outcomes but benefits from designers and their impact on these companies' products, processes or organizational structures.

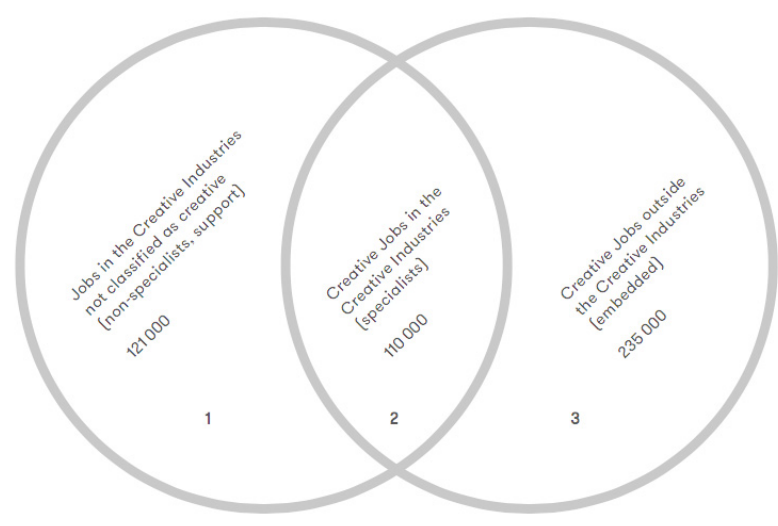

Figure 1. Employment in the creative economy Switzerland, 2016 (Weckerle et al., 2016, p. 65)

This phenomenon, of course is not limited to the design domain or the Swiss territory-it doubtlessly can be described as something that happens all across different markets in the globalizing economy. Also, if you consider how design spread out as a cognitive style or resource for innovation among different fields and disciplines (comp. Kimbell, 2011), creative sectors have become "powerful catalysts for other vital industries" (Ernst \& Young, 2014, p. 27) and the latter realized long ago that design in many cases may become a driver for innovation and economic growth.

Consequently, it doesn't come as a surprise that there is an "increasing tendency to link the role of design to the business world" (Ramírez León, 2015, p. 2150; Espinoza, 2011) bearing a "new generation of designers willing to create their own enterprise" (Guerrini et al., 2015, p. 1706). An alumni survey with feedbacks by 43 Designers (approx. 45\% of alumni contacted) that graduated from our MA program in design between 2010 and 2016, underlines this observation: $58 \%$ stated to work as independent entrepreneurs and a total of $60 \%$ emphasizes that business skills belonged to the most important skills they acquired during their MA studies and should be more supported by the curriculum in design. Furthermore, 20\% specified, that their field of occupation is located outside the classical design domain - a number, which might grow in the following years if considering the uprising occupations identified as Embedded Cratives in the Swiss Creative Economy report (Weckerle et al., 2016, p. 65). These statements again raise the question, if design education has kept up enough with the economic evolution of design and whether the skill-set supported in our current design curricula is enough to meet this change, or "the traditional basic skills associated with designers are no longer sufficient" (Geersbro, 2014). Especially the post-Bolognese subdivision into BA and MA curricula emphasizes this question by asking: when are (design) students really ready to embed into what is more and more becoming a professional field that requires the transfer of knowledge and skills to different issues and disciplines?

\section{Undisciplinary Design-Questioning Discipline-Based Learning}

To find an alternative to the disciplinary point of view on design, which is currently being supported by most of our BA and MA curricula, we set out get a better understanding of the contrary: the Undisciplinary. In his 
Altermanifesto, Nicholas Bourriaud, co-founder and former director of the Palais the Tokyo, proposes his concept of Altermodernity as a "recomposition of a modernity (...) reconfigured according to the specific context within we live "crucially in the age of globalisation"" (Bourriaud, 2009). Further he describes the work of "artists (that) translate and transcode information from one format to another, and wander in geography as well as in history" (Bourriaud, 2009). Craig Bremner and Paul Rodgers take on Bourriaud's discourse and by questioning "the rupturing ad blurring of the design Disciplines" (Bremner \& Rodgers, 2013) they argue for an "Alterplinarity" (Rodgers \& Bremner, 2011) or "Alterdisciplinarity" (Bremner \& Rodgers, 2013), which in a globalized context requires "an ability to make connections that generate new methods to identify 'other' dimensions of design activity and thought" (Bremner \& Rodgers, 2013, p. 12). They further pick up Marshall and Bleecker's concept of "Undisciplinarity" (Marshall \& Bleecker, 2010; Bremner \& Rodgers, 2013) where according to learning expert Stephen Heppell "design practice shifts from being 'discipline-based' to 'issue- or project-based"' (Heppell, 2006).

If we take on Bourriaud's concept of Altermodernity and Bremner and Rodger's description of Undisciplinarity and compare them to what already became a fact in the Swiss Creative Economy, it appears that in the professional world, Swiss creatives are already facing an issue- and project-based understanding of the design domain. And with more than $60 \%$ of Swiss creatives working in an undisciplinary or embedded context, it appears more than clear that design education as well should face this shift towards undisciplinarity.

Besides its link to the business world, an undisciplinary understanding of design in a globalized society also raises the question whether and how Embedded Creatives integrate into different cultural contexts. Design educators Iain MacDonald and Myrna MacLeod confirm that "in an increasingly global economy students must develop an intercultural awareness of themselves and other cultures, a key attribute of global citizenship" (MacDonald \& MacLeod, 2015, p. 1991). The same challenge applies to a post-industrial context where designer's more and more blend in with a generation of design amateurs producing design outcomes by the means of post-industrial manufacturing. Industrial Designer and design historian Paul Atkinson states that "post-industrial manufacturing $\mathrm{n}$ deals with a new kind of designing that has the potential to create a different role for the designer; where design decisions are made jointly or collectively" (Atkinson, 2010, p. 153).

All three challenges - embedding into the industry, acquiring an intercultural awareness and positioning ourselves in a post-industrial context - have in common that designers must assume a certain role that may vary depending on whichever aspect becomes the main driver in a determined situation or context. While developing our successive MA curriculum in design, the potential to question and establish new roles for our students appeared as key to the awkward position between design specialists and an upcoming market of designers that should blend into a variety of industries, cultures and markets.

\section{Re-Arranging the Skillset-The Y-Shaped Designer}

"Blurring the disciplines is good. It offers tremendous possibilities in the hands of anyone with a disciplinary platform of knowledge and skill" (Bremner \& Rodgers, 2013, p. 13). With this statement, Bremner and Rodgers stress the importance of a disciplinary root, which enables to wander out of the discipline into undisciplinary voyages (comp. Bourriaud, 2009). In job-recruitment, this transition has been described with the metaphor of T-shaped personas or T-shaped skills (Guest, 1991; Brown, 2010) (Figure 2) where "the vertical stroke of the T is a depth of skill that allows (...) to contribute to the creative process" and "the horizontal stroke of the $\mathrm{T}$ is the disposition for collaboration across disciplines" (Brown, 2010).

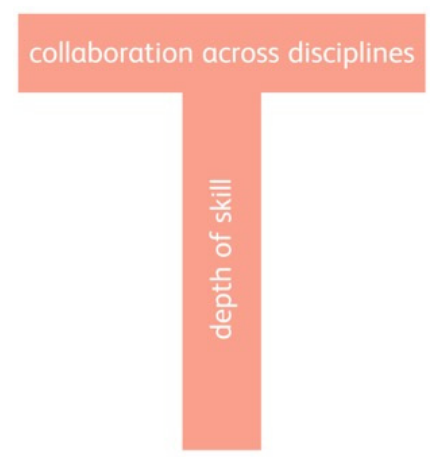

Figure 2. T-shaped skills, as described by Guest and Brown (Guest, 1991; Brown, 2010) 
What has been applied for the professional world still represents a challenge in design education though. On the one hand, in the post-Bolognese curriculum, rather generalist BA programs stand in contradiction to the T-shaped designer since they lack the disciplinary depth of skill, which Bremner and Rodgers mention as a prerequisite to unchain the possibilities of undisciplinarity (comp. Bremner \& Rodgers, 2013). On the other hand, the attempt to provide disciplinary MA programs in Switzerland often fails due to the lacking number of minimum students required, a deficit which mostly is met with programs that combine multiple disciplinary tracks in one curriculum. These programs result to be hard to handle and the "disposition for collaboration across disciplines" that Brown is asking for (Brown, 2010) is hard to train since such curricula often stick to the goal of providing a disciplinary major degree based on a personal (and mostly disciplinary) master project.

Whether BA and MA programs represent complementary or consecutive studies, the missing link, which would facilitate a seamless transition from the depth of skill into the collaborative mode is a repertory of connective competences - competences enabling graduates to embed into an undisciplinary and collaborative working-context. For design education, we therefore "zoomed" into the junction between the vertical and the horizontal stroke (Figure 3) of the T-shape in order to define, what sort of skills might be needed for the transition from disciplinary towards cross-disciplinary working modes. Based upon this reflection, we propose a Y-shaped skill model (Figure 3), which focuses the junction between a disciplinary root and the collaboration across disciplines by shifting the attention towards the perceived role of the designer within the collaborative context (e.g., entrepreneur vs. consultant) as well as towards multimodal literacy (Kress et al., 2001; Kress, 2003; Jewitt, 2006, 2008) as key to transfer the depth of skill to processes of cross-media meaning-making.

The Y-shaped skill model does not intend to replace the model of T-shaped personas. For design education, it rather works as a complementary and more detailed view on what sort of competences students need to acquire to embed their depth of skill into a collaborative and cross-disciplinary context.

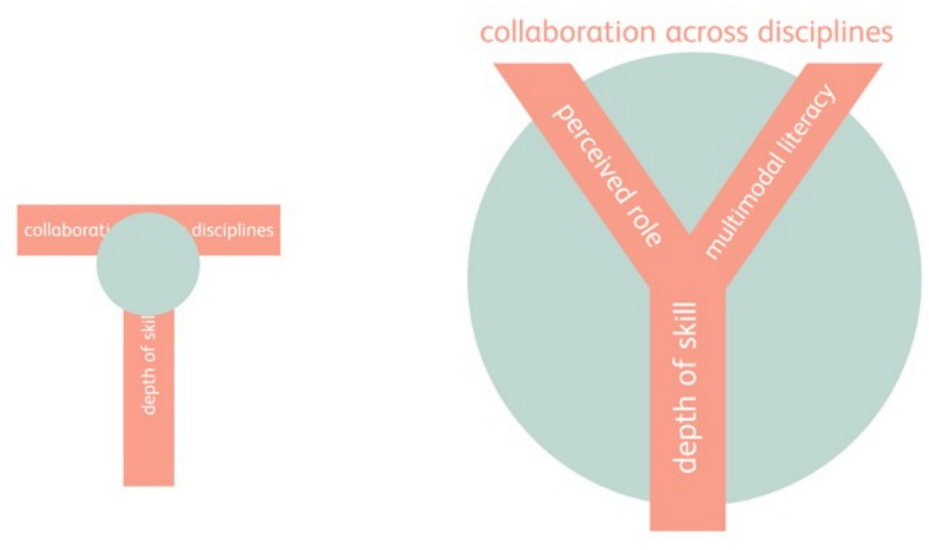

Figure 3. Y-shaped skill model, connective competences, Eckert 2017

In a successive step, we started evaluating our model in a series of sounding boards with representatives of the Swiss professional associations in the design domain, as well as a series workshops with faculty from BA programs in Graphic Design, Illustration, Product Design, Textiles, Camera Arts, Design Management and Service Design. Furthermore, the model has been discussed during a poster session at the "REDO-Cumulus conference, 2017" in Kolding, Denmark. Main outcome of these discussions and workshops has been the approval that at many universities besides Lucerne University of Applied Sciences and Arts, the depth of skill is provided in the BA curriculum and enabling our students to work across disciplines clearly is a goal associated with MA programs (Figure 4). On a more concrete level, goals that have been associated with connective competences and Y-shaped Designers were:

- Perceived role: Position oneself in a wider context of disciplines, theories and practices.

- Being able to identify relevant issues and brief oneself to approach them from a design point of view.

- Being able to transfer a variety of design methods and processes to different domains and applying them at different project stages.

- Knowing different business models and applying the matching one to one's own business case. 
- Having a strong disciplinary root than can be expressed in a transmedial/multimodal approach.

- Embed as team-players into different markets, cultural contexts and post-industrial strategies.

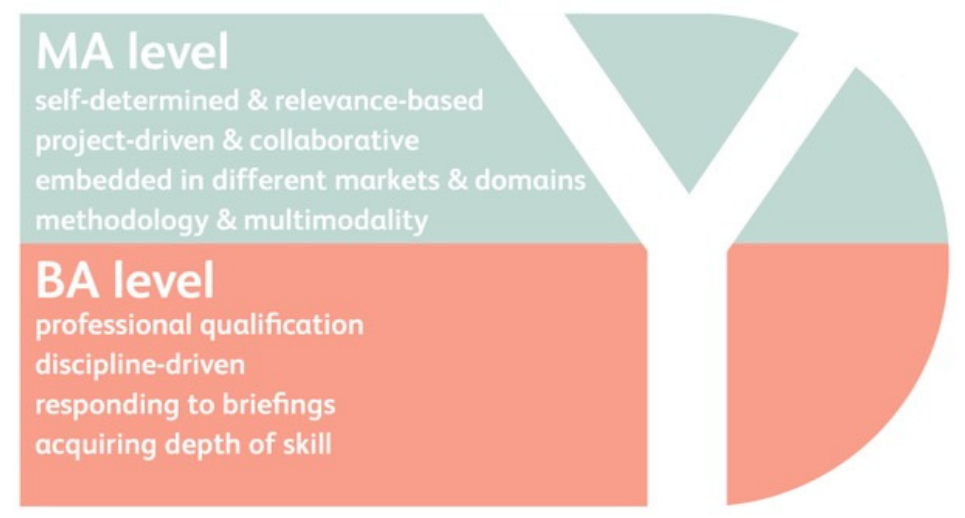

Figure 4. Competences and goals related to BA and MA curricula, Eckert 2017

\section{The Designer's Perceived Role and Multimodal Literacy as Key to Embed into Cross-Media Meaning-Making}

One of the key connecting competences that has been identified while developing our new MA curriculum, is to position oneself in a wider context of disciplines, theories and practices. We described this capability as the designer's perceived role. As reflected above, an extending creative economy in a global, inter-cultural and post-industrial context is continuously forging the designer's role. Therefore, the Y-shaped Designer's better understanding of his or her specific role within this global economy tempts to ease the moment of embedding into a collaborative context. A first attempt of defining a set of roles that serves to develop our MA program's new curriculum proposes three stages of roles:

\section{1) MAKER | RESEARCHER | ENTREPRENEUR \\ 2) CONSULTANT | STRATEGIST | CATALYST \\ 3) BROKER | CULTIVATOR | CURATOR}

The first stage relates to the "creation and distribution of artefacts" (Golsby-Smith, 1996). Its protagonists are the maker, researcher and entrepreneur embedding into the collaborative context as self-determined personas with an author-driven and issue-based understanding of their design outcome. Our second stage proposes the consultant, strategist and catalyst, who relate to the order of "strategic design planning" (Buchanan, 1995; Golsby-Smith, 1996; Buchanan, 2001, 2004) driven by a more human-centered and issue-based approach. As a third stage of roles within the "cultural system" (Buchanan, 1995; Golsby-Smith, 1996; Buchanan, 2001, 2004), we propose the broker, cultivator and curator. Within the collaborative context, they operate on a level of "critical reflexion" (Weckerle et al., 2016), by "making junctions" and "map-making that opens new routes" (Obrist, 2014) for the "homo viator" (Bourriaud, 2009) or designer viator in a globalized creative economy.

As a second connective competence and complementary component to the perceived role of the Y-shaped Designer, we propose multimodal literacy as key to trigger collaboration across disciplines. While semiotician Gunther Kress mainly refers to "multimodality" as a shift from the written word to the image and the book to the screen (Kress, 2003), in our model, we refer to it regarding mainly two aspects: one is our aim to provide our master students "learning (that) traverses institutional boundaries" (Jewitt, 2008, p. 242) and "increasingly involves students in working across different sites of expression, negotiating and creating new flexible spaces for planning, thinking, hypothesizing, testing, designing, and realizing ideas (Jewitt, 2006, 2008, p. 259). The second aspect regards the manifestation of design artefacts across different media. It relates to the term of multiliteracies coined by the New London Group (1996) and an "increasing significance of cultural and linguistic diversity in a global economy and the complexity of texts with respect to nonlinguistic, multimodal forms of representation and communication, particularly, but not limited to, those affiliated with new technologies" (Jewitt, 2008, p. 245) or in simpler words the "'mashing' and 'remixing' in the digital, multimodal mediascape" (Jewitt, 2008, p. 253). 
Based upon these aspects our new curriculum aims to provoke multimodal confrontations from day one on. In practice, our former disciplinary design studio is meant to turn into an undisciplinary and issue-based real-world lab where students expose their projects to a collaborative audience of learners, educators and external tutors coming from different disciplines and working in different media.

\section{Discussion and Future Steps}

By getting a better understanding of what role undisciplinarity might play in a globalized creative economy and which connective competences might help our MA graduates to embed into this constantly changing context, we built a base for the future dialogue between, learners, educators and practitioners in our design curriculum. We started arguing for a more disciplinary BA curriculum that provides the disciplinary depth and an undisciplinary MA curriculum, which is meant to trigger collaboration across disciplines by providing practice- and issue-based learning experiences. To achieve the goal of an undisciplinary MA curriculum in design, we continue to work on the Y-shaped skill model and connective competences on two different levels: one is the identification of situative skills and concrete competences (Kaiser, 2005, 2011) - skills that represent knowledge and abilities, which will be required in concrete practical situations of our graduates (e.g., negotiating skills while working with a large number of stakeholders). Based on these concrete competences we started to derive situative learning goals targeted in our new curriculum. On a second and complementary level, we are currently working on didactical approaches and aspects, which will support achieving these learning goals (Figure 5).

\begin{tabular}{|c|c|c|}
\hline Didactical Aspect & PRE-curriculum & POST-curriculum \\
\hline $\begin{array}{l}\text { Project- and Issue-based } \\
\text { learning }\end{array}$ & $\begin{array}{l}\text { Disciplinary learning-track (e.g. graphic } \\
\text { design) and disciplinary studio-work. }\end{array}$ & $\begin{array}{l}\text { Project- and issue-based design studio. } \\
\text { Taught by a multidisciplinary faculty. }\end{array}$ \\
\hline Collaborative learning & Individual project-work and studio-coaching. & $\begin{array}{l}\text { Collaborative project-work and group-coaching } \\
\text { in the design studio. }\end{array}$ \\
\hline Context-based learning & $\begin{array}{l}\text { One disciplinary project; often approached } \\
\text { from a design-only point of view. }\end{array}$ & $\begin{array}{l}\text { An initial series }\left(1^{\text {st }} \text { semester) of brief }\right. \\
\text { interdisciplinary projects in collaboration with } \\
\text { external partners shifts the attention to the } \\
\text { real-world context. }\end{array}$ \\
\hline Self-determined learning & $\begin{array}{l}\text { Students can choose between a variety of } \\
\text { courses and pick one personal subject for their } \\
\text { project. }\end{array}$ & $\begin{array}{l}\text { Students get involved into the organization of } \\
\text { student-led courses, alumni lessons and focus } \\
\text { groups. Subjects and projects get discussed } \\
\text { collectively by both, learners and educators. }\end{array}$ \\
\hline $\begin{array}{l}\text { Competence-oriented learning } \\
\text { and self-evaluation }\end{array}$ & $\begin{array}{l}\text { Students get evaluated and graded by a set of } \\
\text { criteria. }\end{array}$ & $\begin{array}{l}\text { Students evaluate themselves with a } \\
\text { competence-matrix. Based upon this evaluation a } \\
\text { learning-agreement is made after the } 2^{\text {nd }} \text { semester. } \\
\text { This agreement is part of the final evaluation and } \\
\text { grading as well as the base for an individual } \\
\text { coaching to achieve the established learning-goals. }\end{array}$ \\
\hline External referencing systems & $\begin{array}{l}\text { Students develop their MA project in the } \\
\text { design studio and mainly get taught and } \\
\text { evaluated by the program's own faculty. }\end{array}$ & $\begin{array}{l}\text { During the } 1^{\text {st }} \text { semester, short-projects are held } \\
\text { together with external partners and companies. } \\
\text { During semester } 2 \text { and } 3 \text {, students set up } \\
\text { partnerships for their own project and work at the } \\
\text { partner's or company's site. }\end{array}$ \\
\hline $\begin{array}{l}\text { Learning that traverses } \\
\text { institutional boundaries across } \\
\text { different sites of expression }\end{array}$ & $\begin{array}{l}\text { Students mainly work in the studio and the } \\
\text { university's different labs. }\end{array}$ & $\begin{array}{l}\text { The studio and the lab (newly collocated on the } \\
\text { same floor) merge together. Project-weeks held at } \\
\text { companies' sites and collaborations with external } \\
\text { partners extend the studio into a real-world lab. }\end{array}$ \\
\hline
\end{tabular}

Figure 5. Didactical aspects implemented in pre-post curriculum, Eckert 2017

Overall goal of the defined connective competences, situative learning goals and didactics is to empower learners as self-determined yet collaborative actors of their own learning while being supported by the educator as coach and facilitator, as well as actors from the professional field extending the institutional reference system to what is meant to become a real-world-lab. In terms of employability, this self-determined, practice-based and collaborative approach is meant to support the seamless integration into the growing market of Creative Economies as both, autonomous specialists and Embedded Creatives. Our new MA curriculum in Design will be implemented during winter term 2018/19. First graduates are expected to finish by the year 2020. The further development and implementation of our new MA curriculum is being accompanied by a continuous evaluation consisting in surveys held with students studying in the current and such beginning to study with the future 
curriculum. Furthermore, evaluations will be held with actors from the Swiss Creative Economy aiming at a constantly improving match between our MA program and the real-world requirements in the Creative Industry.

\section{References}

Atkinson, P. (2010). Boundaries? What Boundaries? The Crisis of Design in a Post-Professional Era. The Design Journal, 13(2), 137-155.

Bourriaud, N. (2009). Altermodern Manifesto-Postmodernism is Dead. The Tate Triennial.

Bremner, C., \& Rodgers, P. (2013). Design without Discipline. Design Issues, 29(3), 4-13. https://doi.org/10.1162/DESI_a_00217

Brown, T. (2009). Change by Design: How Design Thinking Transforms Organizations and Inspires Innovation. NY: Harper Business.

Brown, T. (2010). T-Shaped Stars: The Backbone of IDEO's Collaborative Culture. An Interview with IDEO CEO Tim Brown, By Morten T. Hansen. Retrieved January, 2017, from http://chiefexecutive.net/ideo-ceo-tim-brown-t-shaped-stars-the-backbone-of-ideoae ${ }^{\mathrm{TM}_{\mathrm{S}} \text {-collaborative-cultur }}$ e/

Buchanan, R. (1992). Wicked problems in design thinking. Design Issues, 8(2), 5-21. https://doi.org/10.2307/1511637

Buchanan, R. (1995). Rhetoric, humanism, and design. In R. Buchanan, \& V. Margolin (Eds.), Discovering design: Explorations indesign studies (pp. 23-66). Chicago: University of Chicago Press.

Buchanan, R. (2001). Design research and the new learning. Design Issues, 17(4), 3-23. https://doi.org/10.1162/07479360152681056

Buchanan, R. (2004). Design as inquiry: The common, future and current ground of design. In J. Redmond, D. Durling, \& A. de Bono (Eds.), Futureground: Proceedings of the Design Research Society International Conference (pp. 9-16). Melbourne, Australia: Monash University.

Cross, N. (2006). Designerly Ways of Knowing. Springer.

Dunne, D., \& Martin, R. (2006). Design Thinking and How It Will Change Management Education: An Interview and Discussion. Academy of Management Learning \& Education, 5(4), 512-523. https://doi.org/10.5465/AMLE.2006.23473212

Ernst, \& Young. (2014). Creating growth-Measuring cultural and creative markets in the EU. EYGM Limited.

Espinoza, R. (2011). Diseño y negocios. Se rompe un paradigma? Papel del diseñador dentro del los negocios en la ciudad de Buenos Aires, Trabajo práctico Universidad de Palermo Facultad de Diseño y Comunicación.

Geersbro, J. (2014). TEKO Analysis. VIA UC TEKO.

Golsby-Smith, T. (1996). Fourth order design: A practical perspective. Design Issues, 12(1), 5-25. https://doi.org/10.2307/1511742

Guerrini, L., Jarauta, P., \& Rampino, L. (2015). Training and Educating the New Generation of Designers. In The Virtuous Circle, Proceedings of the Cumulus Conference (pp. 1705-1718). Milan.

Guest, D. (1991). The hunt is on for the Renaissance Man of computing. In The Independent.

Heppell, S. (2006). RSA Lectures: Stephen Heppell-Learning 2016. Retrieved January, 2017, from https://vimeo.com/179801906

Jewitt, C. (2006). Technology, literacy and learning: A multimodal approach. London: Routledge.

Jewitt, C. (2008). Multimodality and Literacy in School Classrooms. Review of Research in Education, 32, 241-267. https://doi.org/10.3102/0091732X07310586

Kaiser, H. (2005). Wirksame Ausbildungen entwerfen—Das Modell der Konkreten Kompetenzen. Bern: h.e.p. verlag.

Kaiser, H. (2011). Situative Anforderungen und individuelles Konnen. Retrieved January, 2016, from http://www.hrkll.ch/typo/fileadmin/Texte/SiKo/Anforderung_und_Koennen.pdf

Kimbell, L. (2011). Rethinking Design Thinking: Part 1. Design and Culture, 3(3), 285-306. https://doi.org/10.2752/175470811X13071166525216

Kress, G. (2003). Literacy in the new media age. London, Routledge. https://doi.org/10.4324/9780203164754 
Kress, G., Jewitt, C., Ogborn, J., \& Tsatsarelis, C. (2001). Multimodal teaching and learning: The rhetorics of the science classroom. London, Continuum.

Lawson, B. (2005). How Designers Think. In Fourth Edition: The Design Process Demystified (4th ed.). Architectural Press.

Ma, J. (2015). Meaning Making and the Expanding Scope of Design. In The Virtuous Circle, Proceedings of the Cumulus Conference (pp. 1969-1990). Milan.

Macdonald, I., \& MacLeod, M. (2015). How Can Design Education Develop Intercultural Competencies for Professional Practice and Global Citizenship? In The Virtuous Circle, Proceedings of the Cumulus Conference (pp. 1991-2012). Milan.

Marshall, J., \& Bleecker, J. (2010). Undisciplinarity in Digital Blur: Creative Practice at the Boundaries of Architecture, Design and Art (pp. 216-223, Paul Rodgers \& Michael Smyth, Eds.). Oxon: Libri Publishers.

New London Group. (1996). A pedagogy of multiliteracies: Designing social futures. Harvard Educational Review, 66, 60-92. https://doi.org/10.17763/haer.66.1.17370n67v22j160u

Obrist, H. U. (2014). Ways of Curating. Penguin.

Ramírez León, C. (2015). Towards the Higher Education Relevance. In The Virtuous Circle, Proceedings of the Cumulus Conference (pp. 2150-2167). Milan.

Rittel, H., \& Webber, M. M. (1973). Dilemmas in a General theory of Planning. Policy Sciences, 4, 155-169. https://doi.org/10.1007/BF01405730

Rodgers, P., \& Bremner, C. (2011). Alterplinarity-“Alternative Disciplinarity”. In Future Art and Design Research Pursuits. Studies in Material Thinking (pp. 1-16).

Weckerle, C., Page, R., \& Grand S. (2016). Von der Kreativwirtschaft zu den Creative Economies-Kreativwirtschaftsbericht Schweiz 2016. Zurcher Hochschule der Kunste, Departement Kulturanalysen und Vermittlung.

\section{Copyrights}

Copyright for this article is retained by the author(s), with first publication rights granted to the journal.

This is an open-access article distributed under the terms and conditions of the Creative Commons Attribution license (http://creativecommons.org/licenses/by/4.0/). 